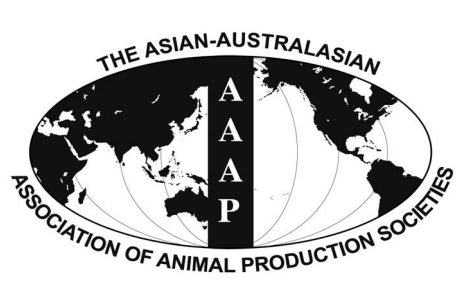

Open Access

Asian Australas. J. Anim. Sci.

Vol. 29, No. 12 : 1761-1767 December 2016

http://dx.doi.org/10.5713/ajas.16.0041

www.ajas.info

pISSN 1011-2367 elSSN 1976-5517

\title{
Effects of Coated Compound Proteases on Apparent Total Tract Digestibility of Nutrients and Apparent lleal Digestibility of Amino Acids for Pigs
}

\author{
L. Pan, P. F. Zhao, Z. Y. Yang, S. F. Long, H. L. Wang, Q. Y. Tian, Y. T. Xu, X. Xu, \\ Z. H. Zhang ${ }^{1}$, and X. S. Piao* \\ State Key Laboratory of Animal Nutrition, Ministry of Agriculture Feed Industry Centre, \\ China Agricultural University, Beijing 100193, China
}

\begin{abstract}
Two experiments were conducted to evaluate effects of coated compound proteases (CC protease) on apparent total tract digestibility (ATTD) of nitrogen (N) and energy, and apparent ileal digestibility (AID) of amino acids (AA) and nutrients in diets for pigs. In Exp. 1, 12 crossbred barrows (initial body weight: $20.14 \pm 1.71 \mathrm{~kg}$ ) were housed in individual metabolism crates and allotted into 2 treatments with 6 piglets per treatment according to weight in a randomized complete block design. The 2 diets were corn-soybean meal basal diets with $(0.2 \mathrm{~g} / \mathrm{kg})$ or without CC protease supplementation. The CC protease supplementation increased $(\mathrm{p}<0.05)$ the digestible and metabolizable $\mathrm{N}$ and energy values and the digestibility and retention rate of $\mathrm{N}$ in the diet. The ATTD of energy and nutrients had been improved $(\mathrm{p}<0.05)$ in the diet supplemented with CC protease. In Exp. 2, 12 crossbred barrows (initial body weight: $20.79 \pm 1.94 \mathrm{~kg}$ ), fitted with T-cannulas at the distal ileum, were blocked by body weight into 2 groups with 6 pigs each. The diets were the same as those in Exp. 1. The CC protease increased $(\mathrm{p}<0.05)$ the AID of crude protein and some essential AA including arginine, isoleucine and leucine. The AID and ATTD of energy and nutrients had been improved $(p<0.05)$ by supplemental CC protease, but the hindgut digestibility of nutrients was unaffected. Overall, the CC protease improved the ATTD of N and energy and AID of some indispensible AA and nutrients in the corn-soybean meal diet for pigs. Therefore, the CC protease supplement could improve the utilization of protein in the corn-soybean meal diet and thus contribute to lower $\mathrm{N}$ excretion to the environment. (Key Words: Amino Acid, Apparent Ileal Digestibility, Apparent Total Tract Digestibility, Coated Compound Proteases, Nitrogen, Pigs)
\end{abstract}

\section{INTRODUCTION}

Soybean meal (SBM) is one of the most commonly used protein sources for pigs. Most of the proteins in SBM are easily digested, but some proteins including glycinin, protease inhibitor and antigenic proteins are difficult to digest, especially for newly weaned pigs, which may damage intestinal health and impair immune function (Brandon and Friedman, 2002; Sun et al., 2008; Zhao et al., 2008; Wang et al., 2011a;b). Fortunately, with the

\footnotetext{
* Corresponding Author: X. S. Piao. Tel: +86-10-62733588, Fax: +86-10-62733688, E-mail: piaoxsh@cau.edu.cn

${ }^{1}$ Kemin Industries (Zhuhai) Co., Ltd., Zhuhai 519040, China.

Submitted Jan. 14, 2016; Revised Mar. 2, 2016; Accepted Mar. 17, 2016
}

developing of feed enzyme technologies, protease treatment of SBM is an alternative means to reduce the antigenic challenge of SBM and improve performance of animals (Rooke et al., 1998; Piao et al., 1999; Yu et al., 2007; Romero et al., 2013). Therefore, the treatment of SBM with appropriate proteases provides a potential method to enhance the utilization of SBM proteins (Adeola and Cowieson, 2011).

Nowadays, increasingly excessive nitrogen emission from animal production has damaged the natural environment and threatened human health both directly and indirectly (He et al., 2006; Shen et al., 2008; Chen et al., 2014). An effective way to improve the nitrogen pollution is enhancing nitrogen digestibility and reducing nitrogen excretion in animal production. Actually, protein sources 
are especially indispensable for pigs (Maxwell and Carter, 2001; Pan et al., 2016). It is, therefore, significant to explore effective proteases to improve the digestibility of protein and thus to decrease nitrogen excretion for successful and sustainable swine production in the future (Brotzge et al., 2014).

Proteases as supplemental feed enzymes have been added to swine diets routinely for many years (Cowieson and Ravindran, 2008; Wang et al., 2011a; b), however, different proteases with different inherent characteristics may elicit divergent responses in vivo (Adeola and Cowieson, 2011). In our studies, the enzyme products were compounded with acidic, neutral and alkaline proteases produced by Aspergillus niger, Bacillus subtilis, and Bacillus Licheniformis and coated by corresponding coating layers, which could successively dissolve and work in different microenvironment in the digestive tract. We hypothesized that the coated compound proteases (CC protease) could improve the utilization of nitrogen $(\mathrm{N})$ in different intestinal segments and thus reduce $\mathrm{N}$ excretion in corn-SBM diet. Therefore, the objective of these studies was to evaluate effects of the CC protease supplementation on apparent total tract digestibility (ATTD) of N and energy, and apparent ileal digestibility (AID) of amino acids (AA) and nutrients in diets for pigs.

\section{MATERIALS AND METHODS}

All procedures used in the experiments were approved by the China Agricultural University Institutional Animal Care and Use Committee (Beijing, China). These studies were conducted in the Metabolism Laboratory of the National Feed Engineering Technology Research Centre (Beijing, China).

\section{Coated compound proteases}

The CC proteases with protease activity of 8,000 units/g were in granular form provided by Kemin Industries Co. Ltd. (Zhuhai, China). One unit of enzyme activity is defined as the amount of enzyme liberating $1 \mu \mathrm{mol}$ of casein per min at $37^{\circ} \mathrm{C}$ and $\mathrm{pH}$ 5.5. The compound enzymes contain acidic, neutral and alkaline proteases produced by Aspergillus niger, Bacillus subtilis and Bacillus Licheniformis, respectively. Three kinds of proteases were coated in order to reduce the impact of feed pelleting and be released in the related gastrointestinal tract. The acidic protease was coated with heat-resisting membrane, and the neutral and alkaline proteases were both coated by heatproof and acidity-resistant coating layers, which were not expected to degrade by the gastric acid. Therefore, the CC proteases could successively dissolve and work in acidic, neutral or alkaline microenvironment in the digestive tract.

\section{Animals, diets and experimental designs}

Exp. 1 was conducted to evaluate the effects of $\mathrm{CC}$ protease on digestible energy (DE) and metabolizable energy (ME) values, N utilization and ATTD of gross energy (GE) and nutrients in corn-SBM diet. Twelve crossbred barrows (Duroc $\times[$ Landrace $\times$ Large White]), with an average body weight of $20.14 \pm 1.71 \mathrm{~kg}$, were housed in individual metabolism crates and allotted into 2 treatments with 6 pigs per treatment according to weight in a randomized complete block design. The base diet was based on corn-SBM (Table 1), and was formulated to meet or exceed the nutrient requirements as recommended by the NRC (1998). The experimental diet was the basal diet supplemented with $\mathrm{CC}$ protease $(0.2 \mathrm{~g} / \mathrm{kg})$. The analyzed composition of the experimental diets is showed in Table 1.

Pigs were housed in an environmentally controlled room $\left(24^{\circ} \mathrm{C} \pm 2^{\circ} \mathrm{C}\right)$ in metabolism cages equipped with a feeder and a nipple drinker, fully slatted floors, a screen floor, and urine trays that allowed for the total, but separate, collection of urine and fecal materials from each pig. Pigs were allowed a $10 \mathrm{~d}$ period to adapt to the metabolism crates and the environmental conditions of the room. During this period, the pigs were fed a commercial diet and feed intake was gradually increased until the daily feed allowance reached $40 \mathrm{~g} / \mathrm{kg}$ of the pig's body weight. During the experimental period, feed allowance was equivalent to $40 \mathrm{~g} / \mathrm{kg}$ of body weight and divided into 2 equal meals (Adeola, 2001).

Exp. 2 was conducted to evaluate the effects of $\mathrm{CC}$ protease on the AID of AA and nutrients in corn-SBM diet. Twelve crossbred barrows (Duroc $\times[$ Landrace $\times$ Large White]), with an average body weight of $20.79 \pm 1.94 \mathrm{~kg}$, were surgically fitted with T-cannulas at the distal ileum using procedures adapted from Stein et al. (1998). After 14 days of recovery, pigs were blocked by body weight into 2 groups with 6 pigs each. The diets were the same as those in Exp. 1.

Pigs were housed in individual pens in an environmentally controlled room $\left(26^{\circ} \mathrm{C}, 70 \%\right.$ humidity $)$. A feeder and a nipple drinker were installed in each pen. Body weight was recorded at the beginning of the experiment. Feed allowance was equivalent to $40 \mathrm{~g} / \mathrm{kg}$ of body weight and divided into 2 equal meals fed at 0800 and 1700 hours each day. Water was available at all time throughout the experiment.

\section{Sample collection and analysis}

In Exp. 1, individual pig body weight was obtained at the beginning of the experiment. The pigs were adapted to experiment diets for $7 \mathrm{~d}$ followed by a $5 \mathrm{~d}$ total collection of feces and urine. Feces was placed in plastic bags (one bag per pig) as soon as they appeared in the metabolism crates and were immediately stored at $-20^{\circ} \mathrm{C}$. A bucket containing 
Table 2. Daily balance of gross energy (GE) and concentration of digestible and metabolizable energy (DE and ME) in basal diet or diet with $0.2 \mathrm{~g} / \mathrm{kg}$ proteases for pigs (Exp. 1)

\begin{tabular}{lcccc}
\hline Item & Control & CC protease & SEM & p-value \\
\hline Daily balance of GE (MJ/d) & & & & \\
$\quad$ GE intake & 14.1 & 14.0 & 0.43 & 0.87 \\
GE in feces & 2.1 & 1.7 & 0.09 & 0.02 \\
GE in urine & 0.45 & 0.40 & 0.06 & 0.58 \\
DE in diet (MJ/kg) & & & & \\
$\quad$ As-fed basis & 14.2 & 14.5 & 0.06 & 0.01 \\
$\quad$ Dry matter basis & 15.8 & 16.3 & 0.07 & $<0.01$ \\
ME in diet (MJ/kg) & & & & \\
As-fed basis & 13.7 & 14.0 & 0.10 & 0.05 \\
Dry matter basis & 15.3 & 15.8 & 0.11 & 0.01 \\
ME/DE & 0.96 & 0.97 & 0.01 & 0.63 \\
\hline
\end{tabular}

CC protease, coated compound proteases; SEM, standard error of the mean.

ME was calculated as GE intake - fecal energy - urinary energy without considering methane loss.

unpaired data with each animal as an experimental unit. Significant differences were declared at $\mathrm{p}<0.05$, and differences at $0.05 \leq p<0.10$ were considered as a trend toward significance.

\section{RESULTS}

Effects of CC protease on energy and $\mathrm{N}$ utilization and ATTD of nutrients in Exp. 1

Pigs fed the corn-SBM diet supplemented with or without CC protease had a similar GE intake (Table 2). The CC protease supplement decreased $(\mathrm{p}<0.05)$ fecal GE loss, and increased $(\mathrm{p}<0.05)$ the DE and ME compared with the basal diet.

Pigs offered CC protease supplementation had a similar

Table 3. Daily balance of nitrogen $(\mathrm{N})$ and concentration of digestible and metabolizable nitrogen (DN and $\mathrm{MN}$ ) in basal diet or diet with $0.2 \mathrm{~g} / \mathrm{kg}$ proteases for pigs (Exp. 1)

\begin{tabular}{lcccc}
\hline Item & Control & CC protease & SEM & p-value \\
\hline Daily balance of N (g/d) & & & & \\
N intake & 23.5 & 24.3 & 0.74 & 0.50 \\
Fecal N excreted & 4.7 & 3.7 & 0.18 & $<0.01$ \\
Urine N excreted & 4.7 & 2.9 & 0.58 & 0.06 \\
Retained N & 14.2 & 17.7 & 1.00 & 0.04 \\
N digestibility & 0.80 & 0.85 & 0.01 & $<0.01$ \\
N retention rate & 0.61 & 0.73 & 0.03 & 0.01 \\
DN in diet (g/kg) & & & & \\
As-fed basis & 22.1 & 24.2 & 0.17 & $<0.01$ \\
Dry matter basis & 24.8 & 27.2 & 0.19 & $<0.01$ \\
MN in diet (g/kg) & & & & \\
As-fed basis & 16.7 & 20.7 & 0.72 & $<0.01$ \\
Dry matter basis & 18.7 & 23.3 & 0.89 & $<0.01$ \\
\hline
\end{tabular}

CC protease, coated compound proteases; SEM, standard error of the mean.
Table 4. Apparent total tract digestibility of nutrients in basal diet or diet supplemented with $0.2 \mathrm{~g} / \mathrm{kg}$ proteases for pigs (Exp. 1)

\begin{tabular}{lcccc}
\hline Item & Control & CC protease & SEM & p-value \\
\hline Dry matter & 0.86 & 0.88 & 0.004 & $<0.01$ \\
Gross energy & 0.85 & 0.88 & 0.004 & $<0.01$ \\
Crude protein & 0.80 & 0.85 & 0.006 & $<0.01$ \\
Organic matter & 0.87 & 0.89 & 0.003 & $<0.01$ \\
\hline CC protease, coated compound & proteases; SEM, standard error of the \\
mean.
\end{tabular}

$\mathrm{N}$ intake, but a decreased $(\mathrm{p}<0.05)$ fecal $\mathrm{N}$ loss by $20.6 \%$ and tended to a decreased $(\mathrm{p}=0.06)$ urinary $\mathrm{N}$ loss (Table $3)$. The $\mathrm{CC}$ protease supplement improved $(\mathrm{p}<0.05)$ the digestibility and retention rate of $\mathrm{N}$ by $5.6 \%$ and $19.9 \%$, respectively. The digestible and metabolizable $\mathrm{N}$ values were increased $(p<0.05)$ by the $\mathrm{CC}$ protease supplementation. The ATTD of DM, GE, CP, and organic matter $(\mathrm{OM})$ in diet supplemented with $\mathrm{CC}$ protease was greater $(\mathrm{p}<0.05)$ than in the basal diet (Table 4$)$.

\section{Effects of CC protease on AID of AA and nutrients in Exp. 2}

The AID of CP was increased $(\mathrm{p}<0.05)$ by $8.8 \%$ in diet with CC protease compared with that in basal diet (Table 5). The CC protease supplementation improved the AID of arginine, histidine, isoleucine, and leucine by $4.9 \%, 14.5 \%$, $6.8 \%$, and $9.3 \%$, respectively. The AID of some dispensable

Table 5. Apparent ileal digestibility of crude protein and amino acids (AA) in basal diet or diet supplemented with $0.2 \mathrm{~g} / \mathrm{kg}$ proteases for pigs (Exp. 2)

\begin{tabular}{lcccc}
\hline Item & Control & CC protease & SEM & p-value \\
\hline $\begin{array}{l}\text { Crude protein } \\
\text { Indispensable AA }\end{array}$ & 0.68 & 0.74 & 0.012 & 0.01 \\
$\quad$ & & & & \\
Arginine & 0.82 & 0.86 & 0.008 & 0.01 \\
Histidine & 0.69 & 0.79 & 0.012 & $<0.01$ \\
Isoleucine & 0.74 & 0.79 & 0.012 & 0.01 \\
Leucine & 0.75 & 0.82 & 0.012 & $<0.01$ \\
Lysine & 0.82 & 0.81 & 0.013 & 0.67 \\
Methionine & 0.82 & 0.85 & 0.013 & 0.08 \\
Phenylalanine & 0.79 & 0.82 & 0.014 & 0.14 \\
Threonine & 0.67 & 0.68 & 0.013 & 0.60 \\
Tryptophan & 0.72 & 0.72 & 0.013 & 0.96 \\
Valine & 0.71 & 0.72 & 0.013 & 0.62 \\
Dispensable AA & & & & \\
Alanine & 0.67 & 0.74 & 0.017 & 0.02 \\
Aspartic acid & 0.75 & 0.76 & 0.011 & 0.38 \\
Cystine & 0.58 & 0.61 & 0.036 & 0.62 \\
Glutamic & 0.76 & 0.79 & 0.022 & 0.28 \\
Glycine & 0.52 & 0.52 & 0.027 & 0.82 \\
Proline & 0.71 & 0.68 & 0.050 & 0.63 \\
Serine & 0.73 & 0.75 & 0.012 & 0.25 \\
Tyrosine & 0.71 & 0.81 & 0.028 & 0.03 \\
\hline CC protease, coan & conp & & & \\
\hline
\end{tabular}

$\mathrm{CC}$ protease, coated compound proteases; SEM, standard error of the mean. 
AA including alanine and tyrosine were also increased by the CC protease.

The AID and ATTD of DM, GE, and CP were greater $(p<0.05)$ in corn-SBM diet supplemented with CC protease than those in basal diet, but the HGD of these nutrients was not different between treatments (Table 6). There was no difference in AID and HGD of OM between the diets, but the ATTD of OM increased in diet supplemented with $\mathrm{CC}$ protease.

\section{DISCUSSION}

The need to reduce the $\mathrm{N}$ content in the livestock wastewater is more important than any time previously (Chen et al., 2014). The reductions in $\mathrm{N}$ excretion are mostly attributed to changes in both urinary and fecal $\mathrm{N}$ excretion in animal production (Dong et al., 2014). The provision of a low $\mathrm{CP}$ diet could result in a reduction in $\mathrm{N}$ excretion (O'Connell et al., 2006); however, it is indispensible to provide sufficient $\mathrm{N}$ sources to meet the AA requirements for pigs. Therefore, the method of maximizing the potential available $\mathrm{N}$ in the existing diet is very significant. The use of exogenous protein enzymes in swine diets is a common strategy to ameliorate anti-nutritive effects of SBM and to improve the efficiency of $\mathrm{N}$ utilization (Kong et al., 2015).

Supplementation of diets with exogenous enzymes to stimulate nutrient digestion and minimize or eliminate the negative effect of anti-nutritional factors has attracted considerable interest within the modern pig industry (Jo et al., 2012). It has been proved that treatment of SBM with

Table 6. Apparent ileal (AID), total tract digestibility (ATTD) and hindgut digestibility (HGD) of nutrients in basal diet or diet supplemented with $0.2 \mathrm{~g} / \mathrm{kg}$ proteases (Exp. 2)

\begin{tabular}{lcccc}
\hline Item & Control & CC protease & SEM & p-value \\
\hline Dry matter & & & & \\
$\quad$ AID & 0.64 & 0.69 & 0.011 & $<0.01$ \\
ATTD & 0.81 & 0.85 & 0.007 & $<0.01$ \\
$\quad$ HGD & 0.16 & 0.15 & 0.009 & 0.40 \\
Gross energy & & & & \\
$\quad$ AID & 0.66 & 0.71 & 0.011 & 0.01 \\
ATTD & 0.79 & 0.84 & 0.007 & $<0.01$ \\
HGD & 0.13 & 0.13 & 0.008 & 0.93 \\
Crude protein & & & & \\
$\quad$ AID & 0.68 & 0.74 & 0.012 & 0.01 \\
ATTD & 0.76 & 0.83 & 0.014 & 0.01 \\
$\quad$ HGD & 0.08 & 0.09 & 0.017 & 0.79 \\
Organic matter & & & & \\
AID & 0.68 & 0.72 & 0.014 & 0.14 \\
ATTD & 0.83 & 0.86 & 0.008 & 0.04 \\
HGD & 0.15 & 0.14 & 0.015 & 0.84 \\
\hline
\end{tabular}

$\overline{\mathrm{CC}}$ protease, coated compound proteases; SEM, standard error of the mean. appropriate proteases may improve piglet performance at weaning, which would be a potential method for increasing the amounts of SBM in starter diets for weaned piglets (Rooke et al., 1998). Protease had a positive effect on the ATTD of DM, GE, and CP in weaned piglets (Wang et al., 2011a). However, there are still some insignificant proteases in diets ( $\mathrm{Ji}$ et al., 2008; Adeola and Cowieson, 2011; O'Shea et al., 2014). The effectiveness of supplying enzyme in pig diets may vary because of the difference of ingredients, age of pigs or enzyme products (Ji et al., 2008). In our study, the compound enzymes containing acidic, neutral and alkaline proteases could successively dissolve and work in acidic, neutral or alkaline microenvironment in the digestive tract, which is a novel and attractive method that proved effective in the corn-SBM diet for pigs.

There was no difference in the DM and GE intake in our study, which meant the pigs in the two treatments were under almost the same physical condition. The fecal GE loss for pigs fed with $\mathrm{CC}$ protease supplementation was lower than those fed with the basal diet. This indicated that there was greater DE and ATTD of GE and nutrients in diet supplemented with $\mathrm{CC}$ protease, which were successively confirmed by our results. More importantly, the exogenous enzyme supplementation reduced the fecal $\mathrm{N}$ excretion and increased $\mathrm{N}$ digestibility and retention rate. This may indicated an improvement of the ATTD of CP. Actually, the increased AID of $\mathrm{CP}$ and some AA in Exp. 2 had also supported the results. The ATTD of DM, GE, CP, and OM in Exp. 1 was improved by the protease supplementation, which was the same pattern followed by the results measured using the exogenous indicator method in Exp. 2. The numeric differences of the ATTD of nutrients between the two experiments may be attributed to the different methods for collecting and analyzing fecal samples. Certainly, the different physiological conditions of pigs with or without fistula surgery may also result in differences. Actually, the effects of the CC protease on improving the nutrient digestibility were consistent with each other.

Interestingly, it was not our expectation that the proteases, without any amylase or other side-activities capable of degrading starch, would be capable of improving energy digestibility. A similar unexpected but exciting effects were also detected in broilers fed with sorghum with exogenous protease (Selle et al., 2013). Perhaps the coating proteases degraded a significant portion of the indigestible protein in the soybean-meal and thus resulted into greater digestibility of energy and nutrients.

In the current study, the CC protease supplementation improved the AID of some essential AA including arginine, histidine, isoleucine and leucine, and some non-essential AA including alanine and tyrosine. The other AA, especially lysine, tryptophan and threonine, were least responsive to $\mathrm{CC}$ protease supplementation, which means 
that improvements in digestibility of these AA in practical diets are limited. Therefore, the most limiting essential AA supplementation should be considered independently to avoid overestimating the contribution of the enzymes on the limiting AA when diets supplemented with exogenous enzymes are formulated.

The economic benefit of the use of exogenous proteases is through improvement in the digestibility of dietary AA (Romero et al., 2013). The primary mechanism for this increment appears to be the augmentation of dietary protein hydrolysis and increased protein solubility (Caine et al., 1998). Conclusive evidence is not available supporting a positive or negative change in endogenous secretions caused by exogenous proteases (Romero et al., 2013). We assume that the coating proteases can work in different intestine segments to cover the deficit of the endogenous enzyme and thus improve the nutrients digestibility.

There was greater AID and ATTD of DM, GE and CP in corn-SBM diet supplemented with CC protease, but the HGD of these nutrients was not different between treatments. These findings suggested that the effects of the proteases on hydrolysis of protein were mostly taking place in the small intestine rather than in the hindgut. Maybe the proteases have been inactivated or completely degraded, or disturbed by the microorganisms in the large intestine. As the availability of protein post-caecum is considered to be negligible, an improvement in AID of nutrients, especially $\mathrm{CP}$, can be interpreted as beneficial, as it suggests more energy and protein is available to meet the growth demands of the pig (Romero et al., 2013). Therefore, the greater proportion of nutrients, especially energy or proteins, that are available in the small intestine from diet inclusion of $\mathrm{CC}$ protease the more beneficial and significant they will be.

\section{CONCLUSION}

The CC protease supplementation improved the ATTD of $\mathrm{N}$ and energy and AID of some indispensible AA and nutrients in the corn-SBM diet for pigs. Therefore, the $\mathrm{CC}$ protease supplement could improve the utilization of protein in the corn-SBM diet and thus contribute to lower $\mathrm{N}$ excretion to the environment.

\section{CONFLICT OF INTEREST}

We certify that there is no conflict of interest with any financial organization regarding the material discussed in the manuscript.

\section{ACKNOWLEDGMENTS}

The study was financially supported by the National Natural Science Foundation of China (No. 31372316) and the National Science \& Technology Pillar Program during the Twelfth Five-year Plan Period (2013BAD10B01) and the 111 Project (B16044).

\section{REFERENCES}

Adeola, O. 2001. Digestion and balance techniques in pigs. In: Swine Nutrition (Eds. A. J. Lewis and L. L. Southern) 2nd edn. CRC Press, New York, USA. pp. 903-916.

Adeola, O. and A. J. Cowieson. 2011. Board-invited review: opportunities and challenges in using exogenous enzymes to improve non-ruminant animal production. J. Anim. Sci. 89:3189-3218.

Brandon, D. L. and M. Friedman. 2002. Immunoassays of soy proteins. J. Agric. Food Chem. 50:6635-6642.

Brotzge, S. D., L. I. Chiba, C. K. Adhikari, H. H. Stein, S. P. Rodning and E. G. Welles. 2014. Complete replacement of soybean meal in pig diets with hydrolyzed feather meal with blood by amino acid supplementation based on standardized ileal amino acid digestibility. Livest. Sci. 163:85-93.

Caine, W. R., M. W. A. Verstegen, W. C. Sauer, S. Tamminga, and H. Schulze. 1998. Effect of protease treatment of soybean meal on content of total soluble matter and crude protein and level of soybean trypsin inhibitors. Anim. Feed Sci. Technol. 71:177-183.

Chen, J., Q. Nie, Y. Zhang, J. Hu, and L. Qing. 2014. Ecophysiological characteristics of pistia stratiotes and its removal of pollutants from livestock wastewater. Water Sci. Technol. 69:2510-2518.

Cowieson, A. J. and V. Ravindran. 2008. Effect of exogenous enzymes in maize-based diets varying in nutrient density for young broilers: growth performance and digestibility of energy, minerals and amino acids. Br. Poult. Sci. 49:37-44.

Dong, R. L., G. Y. Zhao, L. L. Chai, and K. A. Beauchemin. 2014. Prediction of urinary and fecal nitrogen excretion by beef cattle. J. Anim. Sci. 92:4669-4681.

He, L. S., H. L. Liu, B. D. Xi, and Y. B. Zhu. 2006. Enhancing treatment efficiency of swine wastewater by effluent recirculation in vertical-flow constructed wetland. J. Environ. Sci. 18:221-226.

Ji, F., D. P. Casper, P. K. Brown, D. A. Spangler, K. D. Haydon, and J. E. Pettigrew. 2008. Effects of dietary supplementation of an enzyme blend on the ileal and fecal digestibility of nutrients in growing pigs. J. Anim. Sci. 86:1533-1543.

Jo, J. K., S. L. Ingale, J. S. Kim, Y. W. Kim, K. H. Kim, J. D. Lohakare, J. H. Lee, and B. J. Chae. 2012. Effects of exogenous enzyme supplementation to corn- and soybean meal-based or complex diets on growth performance, nutrient digestibility, and blood metabolites in growing pigs. J. Anim. Sci. 90:3041-3048.

Kong, C., C. S. Park, and B. G. Kim. 2015. Effects of an enzyme complex on in vitro dry matter digestibility of feed ingredients for pigs. Springerplus 4:261.

Maxwell, C. V. and S. D. Carter. 2001. Feeding the weaned pig. In: Swine Nutrition (Eds. A. J. Lewis and L. L. Southern). 2nd edn. CRC Press, Washington, DC, USA. pp. 691-715.

McDonnell, P., C. O'Shea, S. Figat, and J. V. O’Doherty. 2010. Influence of incrementally substituting dietary soya bean meal 
for rapeseed meal on nutrient digestibility, nitrogen excretion, growth performance and ammonia emissions from growingfinishing pigs. Arch. Anim. Nutr. 64:412-424.

NRC (National Research Council). 1998. Nutrient Requirements of Swine, 10th edn. National Academies Press, Washington, DC, USA.

O'Connell, J. M., J. J. Callan, and J. V. O’Doherty. 2006. The effect of dietary crude protein level, cereal type and exogenous enzyme supplementation on nutrient digestibility, nitrogen excretion, faecal volatile fatty acid concentrations and ammonia emission from pigs. Anim. Feed Sci. Technol. 127:73-88.

O'Shea, C. J., P. O. Mc Alpine, P. Solan, T. Curran, P. F. Varley, A. M. Walsh, and J. V. O. Doherty. 2014. The effect of protease and xylanase enzymes on growth performance, nutrient digestibility, and manure odour in grower-finisher pigs. Anim. Feed Sci. Technol. 189:88-97.

Piao, X. S., I. K. Han, J. H. Kim, W. T. Cho, Y. H. Kim, and C. Liang. 1999. Effects of Kemzyme, phytase and yeast supplementation on the growth performance and pollution reduction of broiler chicks. Asian Australas. J. Anim. Sci. 12:36-41.

Pan, L., X. K. Ma, H. L. Wang, X. Xu, Z. K. Zeng, Q. Y. Tian, P. F. Zhao, S. Zhang, Z. Y. Yang, and X. S. Piao. 2016. Enzymatic feather meal as an alternative animal protein source in diets for nursery pigs. Anim. Feed Sci. Technol. 212:112-121.

Romero, L. F., C. M. Parsons, P. L. Utterback, P. W. Plumstead and V. Ravindran. 2013. Comparative effects of dietary carbohydrases without or with protease on the ileal digestibility of energy and amino acids and AMEn in young broilers. Anim. Feed Sci. Technol. 181:35-44.

Rooke, J. A., M. Slessor, H. Fraser, and J. R. Thomson. 1998. Growth performance and gut function of piglets weaned at four weeks of age and fed protease-treated soya-bean meal. Anim. Feed Sci. Technol. 70:75-190.

Selle, P. H., S. Y. Liu, J. Cai, and A. J. Cowieson. 2013. Steampelleting temperatures, grain variety, feed form and protease supplementation of mediumly ground, sorghum-based broiler diets: influences on growth performance, relative gizzard weights, nutrient utilization, starch and nitrogen digestibility. Anim. Prod. Sci. 53:378-387.
Shen, Y., W. Yuan, Z. Pei, and E. Mao. 2008. Culture of microalga Botryococcus in livestock wastewater. Trans. ASABE 51:1395-1400.

Stein, H. H., B. Seve, M. F. Fuller, P. J. Moughan, and C. F. de Lange. 2007. Invited review: Amino acid bioavailability and digestibility in pig feed ingredients: Terminology and application. J. Anim. Sci. 85:172-180.

Stein, H. H., C. F. Shipley, and R. A. Easter. 1998. Technical note: a technique for inserting a T-cannula into the distal ileum of pregnant sows. J. Anim. Sci. 76:1433-1436.

Sun, P., D. Li, Z. Li, B. Dong, and F. Wang. 2008. Effects of glycinin on Ig E-mediated increase of mast cell numbers and histamine release in the small intestine. J. Nutr. Biochem. 19:627-633.

Thiex, N. J., H. Manson, S. Anderson, and J. A. Persson. 2002. Determination of crude protein in animal feed, forage, grain, and oilseeds by using block digestion with copper catalyst and steam distillation into boric acid: collaborative study. J. AOAC Int. 85:309-317.

Wang, D., X. S. Piao, Z. K. Zeng, T. Lu, Q. Zhang, P. F. Li, L. F. Xue, and S. W. Kim. 2011a. Effects of keratinase on performance, nutrient utilization, intestinal morphology, intestinal ecology and inflammatory response of weaned piglets fed diets with different levels of crude protein. Asian Australas. J. Anim. Sci. 24:1718-1728.

Wang, D., Z. K. Zeng, X. S. Piao, P. F. Li, L. F. Xue, Q. Zhang, X. Han, H. Y. Zhang, B. Dong, and S. W. Kim. 2011b. Effects of keratinase supplementation of corn-soybean meal based diets on apparent ileal amino acid digestibility in growing pigs and serum amino acids, cytokines, immunoglobulin levels and loin muscle area in nursery pigs. Arch. Anim. Nutr. 65:290-302.

Williams, C. H., D. J. David, and O. Iismaa. 1962. The determination of chromic oxide in faeces samples by atomic absorption spectrophotometry. J. Agric. Sci. 59:381-385.

Yu, B., S. T. Wu, C. C. Liu, R. Gauthier, and P. W. S. Chiou. 2007. Effects of enzyme inclusion in a maize-soybean diet on broiler performance. Anim. Feed Sci. Technol. 134:283-294.

Zhao, Y., G. X. Qin, Z. W. Sun, X. D. Zhang, N. Bao, T. Wang, B. Zhang, B. L. Zhang, D. Zhu, and L. Sun. 2008. Disappearance of immunoreactive glycinin and $\beta$-conglycinin in the digestive tract of piglets. Arch. Anim. Nutr. 62:322-330. 